\title{
A Study on Eating-Out Style and Acceptance Intention of Artificial Seasoning: The Moderating Role of Consumers' Psychological Value
}

\author{
Seong-Soo CHA ${ }^{1}$, Bo-Kyung SEO ${ }^{2}$
}

Received: February 08, 2019 Revised: February 18, 2019 Accepted: September 24, 2019

\begin{abstract}
This study aims to investigate the effect of eating-out types on the acceptance intention of artificial seasoning when consumers eat out at restaurants. Eating-out types considered to be typical when customers visit restaurants, such as the food-exploratory type, healthoriented type, and convenience-seeking type, were studied. Based on the research of previous studies, three eating-out types were selected for the study, which were "food-exploratory", "convenience-seeking", "health-oriented". This study was conducted by AMOS 22.0 with 300 questionnaires, and the Structural Equation Model (SEM) was used for examining the hypotheses as statistical method in this study. As a result, eating-out types such as "food-exploratory" and "convenience-seeking" were found to significantly affect the acceptance intention of artificial seasoning. However, consumers' acceptance intention of artificial seasoning differed depending on their consumption value. The path coefficients from food-exploratory type and health-oriented type to acceptance intention were more significant in the hedonic-oriented group than the utilitarian-oriented group. The results of this study suggest eating-out types relate to acceptance intention of artificial seasoning and provide meaningful implications for consumers' psychological consumption value when they consider artificial seasoning.
\end{abstract}

Keywords : Eating-out Type, Food-exploratory, Health-oriented, Convenience-seeking, Psychological Value, Hedonic Value, Utilitarian Value

JEL Classification Code : D11, D12, L66, L81

\section{Introduction}

Recently, dietary culture has changed greatly owing to women's social participation, the nuclear family, and singleperson households. As the proportion of processed food increases, there is a trend toward generalization of the menu and simplification of food. As a result, the use of seasonings has been increasing, and consumption of seasonings having highly natural material content, considered to be healthy, as well as tasty, is increasing. In 1908, Ikeda discovered a

1 First Author, Assistant Professor, Dept. of Food Science \& Service, College of Bio-Convergence, Eulji University, Korea. +82-31-740-7274, Email: sscha@eulji.ac.kr

2 Assistant Professor, Dept. of Food Science \& Service, College of Bio-Convergence, Eulji University, Korea. +82-31-740-7274, Email: sscha@eulji.ac.kr

(c) Copyright: Korean Distribution Science Association (KODISA) This is an Open Access article distributed under the terms of the Creative Commons Attribution Non-Commercial License (http://Creativecommons.org/licenses/by-nc/4.0/) which permits unrestricted noncommercial use, distribution, and reproduction in any medium, provided the original work is properly cited. component of Glutamic Acid (GA) in water, and that produced some flavor. Later, in Japan, these taste components were expressed in Umami and used in various processed foods in the form of food additives. Since the 2000s, seasonings have been developed by various food companies and research institutes.

Seasoning is mainly composed of basic seasonings such as salt, vinegar, soy sauce, monosodium glutamate (MSG), and nucleic acid seasoning, and now, natural seasoning and yeast-fermented seasoning are the mainstream. In addition, the Korean seasoning market has been developing customizing seasonings for use in the total seasoning and development of seasoning materials that are similar to natural ones. Monosodium glutamate (MSG), which is used to enhance the taste of food, is a substance that binds glutamic acid, a kind of amino acid, and is a flavor enhancer. Especially because of its low cost and excellent taste, it has been used as an additive in food processing, as well as in home and restaurant companies in all countries (Kim, Kim, \& Cho, 2013). In 1968, however, Chinese restaurant 
syndrome (CRS) raised concerns about the safety of MSG. As a result, the Food and Drug Administration (FDA), Federation of American Societies for Experimental Biology (FASEB), Food and Agriculture Organization of the United Nations (FAO), and the World Health Organization (WHO) have conducted various experiments and studies on safety (Freeman, 2006; Beyreuther, Biesalski, Fernstrom, Grimm, Hammes, Heinemann, \& Walker, 2007).

In Korea, the Korea Food Safety Research Institute and the Korea Food \& Drug Administration have recognized MSG as Generally Recognized as Safe (GRAS) (Kil \& Jin, 2015). Despite various studies showing that MSG is not scientifically harmful, consumers' negative perceptions continue to spread; as consumers are increasingly interested in health, the use of MSG at home is steadily decreasing, while the preference for natural seasoning is evident. On the other hand, the use of chemical seasoning is increasing in the foodservice industry based on the reduction of the unit price for food and management costs (Chung, Yang, Shin, \& Chung, 2016). In terms of the market size of processed seasonings recently, we can see the preference and interest of domestic consumers for environmentally friendly seasoning by comparing the 50 billion won for natural seasoning, 70 billion won for complex seasoning, and 45 billion won for fermented seasoning. Despite the changes in the external environment of the seasoning market, studies of MSG are primarily based on the perception of MSG use (Choi, 2005; Jeong \& Jeong, 2009; Kim et al., 2013). Moreover, most of the previous research on eating-out style has been conducted on the basis of Korean food (Kim, 2010), wine (Lim \& Yoon, 2006), and customer behavior (Van, 2008). However, specific studies on the relationship between eating-out styles and acceptance intention of MSG had not yet been conducted. The purpose of the study is to varify the relationship between consumers' eating-out style and acceptance intention of artificial seasoning used in the foodservice industry. In addition, through the moderating roles of hedonic value and utilitarian value, this study seeks to clarify the role of the psychological consumption value of restaurant customers in eating-out style and acceptance intention of artificial seasoning. It also supplies basic data to help food additive manufacturers and restaurant managers secure market competitiveness by positively responding to the changing market environment and consumers.

\section{Theoretical Background}

\subsection{Type of Eating-out Style}

Grunert, Brunso, and Bisp (1993) developed a lifestyle measurement tool called Food-related Lifestyle (FRL) in order to understand consumers' behavior patterns. In this study, a cultural cross-comparison was conducted among the three European cities of Paris, London, and Copenhagen, and the factors of lifestyle related to food were classified into shopping and food preparation type, among others. The dietary lifestyle was classified into five factors, including food exploration type, convenience pursuit type, taste pursuit type, qualitative pursuit type, and habitual foodseeking type. Foodservice-consuming attitudes according to dietary lifestyle were classified into five categories: mealcare type, taste-seeking type, food exploration type, wellness-seeking type, and convenience-seeking type. Lifestyle means the behavior pattern that arises from family or individual values. Today, lifestyles are used in marketing to identify changes in consumer behavior and purchasing behavior, and to develop products and services by predicting purchase decisions and consumption behavior. There is a tendency to segment the market according to a specific lifestyle approach that seeks to identify a lifestyle unique to a product or service market, rather than a general lifestyle approach based on a universal lifestyle (Myung, Nam, \& Park, 2016).

\subsubsection{Food Exploratory Type}

The food exploratory type represented the greatest number of people aged 20-29, and the type with the highest preference for processed rice was the food exploratory type, and it was also the type most influenced by food recommendations. Kim and Kim (2010) classified the influence of the housewives' lifestyle on consumption behavior into five factors: health-seeking, convenienceseeking, safety-seeking, fashion-seeking, and taste-seeking. People with a trend-seeking style of eating out often had more than four million won in monthly household income, which means that they could afford economically to follow trends. In addition, people with a trend-seeking tendency were more likely to purchase food products on the market and included the highest ratio of people considering brand names. Based on the above previous studies, the following hypothesis can be formulated:

H1: The food exploratory eating-out type will have a significant influence on acceptance intention of artificial seasoning.

\subsubsection{Health-Oriented Type}

Park, Park, and Oh (2011) classified the factors of eating-out motive and choice of restaurants into seven factors according to lifestyle, including independent lifestyle type, culture-oriented living type, well-beingoriented living type, youth-oriented living type, familyoriented living type, active living type, and shoppingoriented type. Moreover, the factors classified into three types according to the type of restaurant use, including passive lifestyle, relationship-oriented, and pleasure-seeking. The pleasure-seeking type was classified as a group that regarded the quality of food as more important, tried to look younger, and pursued health and well-being. This group also showed a high level of education and income in demographic characteristics and eating-out consumption form. Lifestyle was categorized as more than six factors in 
the effect of women's lifestyle and well-being perception on eating-out behavior intention, including pursuit of fashion, pursuit of livelihood, pursuit of better life, seeking to maintain health, seeking cultural life, and purchasing wellbeing products. Better life-seeking groups favored the pursuit of livelihood and health and favored healthy foods such as environmentally friendly foods and foods for wellbeing. Choe and Kang (2005) have shown that the higher level of educated consumers, the higher the perception of eating less calorie, salt and fat. Kim (2010) proved the factors affecting satisfaction and revisited their classification as health-seeking, convenience-seeking, safety-seeking factor, economy-seeking, and taste-seeking. Therefore, the following hypothesis can be formulated:

H2: The health-oriented eating-out type will have a significant influence on the acceptance intention of artificial seasoning.

\subsubsection{Convenience-Seeking Type}

Buckley, Cowan, and McCarthy's (2007) study, based on the identification of convenience lifestyle factors, identified four segments of consumers: convenience-seeking grazers (33\%), food connoisseurs (26\%), home meal preparers $(25 \%)$, and kitchen evaders (16\%). In particular, convenience-seeking grazers and kitchen evaders were identified as convenience-seeking segments. Rohm and Swaminathan (2004) suggested the existence of four shopping types. These four types were labeled balanced buyers, variety seekers, convenience shoppers, and storeoriented shoppers. The convenience shopper was more motivated by convenience. Convenience-oriented shopping includes the convenient purchase of a product (food, in particular) that is easy to prepare and generally available in small quantities; consumption is quick and immediate (Swoboda \& Morschett, 2001). According to Schultz (1993), personal motivation for choice of goods is explained by physical comfort or convenience, pleasure, relief from fear, satisfaction of ownership instinct, and satisfaction of selfesteem. Purchasing motives are classified into emotional motives and rational motives. Emotional motives are explained by desire, ambition, prestige, affection, curiosity, imagination, differentiation, while rational motives are explained by rationality, convenience, and economic price. Cha and Lee (2018) verified in their research that the factor convenience has a significant influence on consumers' satisfaction, purchasing meal kit at stores. Based on the above previous studies, the following hypothesis is presented.

H3: The convenience-seeking eating-out type will have a significant influence on acceptance intention of artificial seasoning.

\subsection{Moderating Role of Psychological Consumption Value}

Hedonic value exerted more influence on experimental attribute than on practical attribute importance of shopping malls. Additionally, utilitarian was found to have more influence on practical attributes than on the experimental properties of shopping malls (Cha \& Park, 2017). The value of hedonic consumption is the emotional attribute to pursue happiness, fantasy, sensation, and pleasure (Hirschman \& Holbrook, 1982). It is to enjoy the sensuous and experiential process of eating out, rather than simply purchasing a product (Babin, Griffin, \& Babin, 1994). In contrast, utilitarian consumption values are motivations as tasks (Fischer \& Arnold 1990; McGrath, Sherry, \& Levy, 1993). Hedonic consumer behavior reflects the potential entertainment and emotional aspects of purchasing (Bellenger, Steinberg, \& Stanton, 1976), while utilitarian consumption behavior is explained by words such as "work, work-related, [and] rational" (Batra \& Ahotola, 1991). When consumers consume goods, pleasant products offer pleasure and excitement for consumers with more sensory consumption (Hirschman \& Holbrook, 1982). Practical products, on the other hand, provide mechanical and practical elements for functional products such as washing machines and computers. Then, the hedonic attribute is an experimental and sensory experience, and the utilitarian attribute is consumed as a means to more cognitive, instrumental, and functional task performance (Strahilevitz \& Myers, 1998). Emotional value-oriented customers consider brand and atmosphere more important than functional value-oriented customers (Cha \& Seo, 2018). Therefore, the following hypothesis can be formulated:

H4: The effects of eating-out type on the acceptance intention of artificial seasoning will depend on the psychological consumption value.

These hypotheses are presented in Figure 1. below.

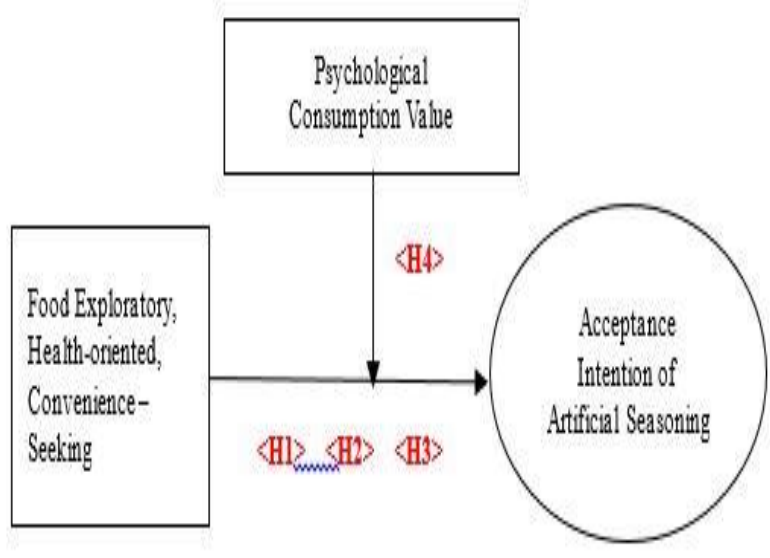

Figure 1: Study Model 


\section{Methodology}

The selection of questionnaire questions was reviewed with reference to the questionnaire used in previous research data, revised, and supplemented according to the present study. The questionnaire was conducted to verify the hypothesis of the research model. The questionnaire from former studies were revised to fit the research purpose of the study. From February 1 to 25, 2018, the questionnaires were administered using on-line survey methods (including Facebook and Kakaotalk). A total of 302 questionnaires were collected and, after excluding two unreliable or incomplete responses, a total of 300 questionnaires were used for further empirical analysis. The study was performed with the following analysis. First, using Amos 22.0, among the measured variables, to investigate the convergence and discriminant validity exploratory factor analysis was conducted. And the non-compliant factors were eliminated, and the confirmatory factor analysis was conducted again using Amos 22.0. Next, covariance structure model analysis was performed for the hypothesis testing of the study. Of the total 300 respondents, 132 (44\%) were males and $168(56 \%)$ were females. Many respondents were in their 20s (71.7\%); professionally, most of them were students $(57.1 \%)$ and workers $(33.7 \%)$.

\section{Results}

\subsection{Evaluation}

First, reliability analysis and validity analysis were performed in multiple items (Churchill, 1979). Exploratory factor analysis was performed to evaluate reliability, validity, and Cronbach's alpha was examined. Based on Eigenvalue 1 , factors were extracted. The VARIMAX method was applied to the factor rotation method. Tables 1 and 2 show the results of the analysis.

As shown in Table 1, Cronbach's alpha coefficients are all over 0.7 , which confirms reliability (Nunnally \& Bernstein, 1978). Exploratory factor analysis confirmed discriminant validity and convergence validity.

As shown in Table 2, the chi-square value of the measurement model is significant $(p=0.00)$, but it is sensitive to the model sample size and complexity. Then, it is necessary to evaluate the model fit in consideration of the normedfit index (NFI) and the comparative fit index (CFI) (Bearden, Sharma, \& Teel, 1982; Bagozzi \& Yi, 1988). The average variance extracted (AVE) and composite reliability (CR) satisfied the criteria proposed by Bagozzi and Yi (1988) (above 0.5 for AVE, above 0.6 for CR), and the factor loadings were statistically significant $(p<0.01)$. The convergent validity was confirmed.
Table 1: Exploratory factor analysis

\begin{tabular}{|c|c|c|c|c|}
\hline & \multicolumn{4}{|c|}{ Variables } \\
\hline & Seasoning & Exploration & Health & Convenience \\
\hline Seasoning 1 & .846 & .229 & .010 & .160 \\
\hline Seasoning 2 & .850 & .082 & -.061 & .139 \\
\hline Seasoning 3 & .800 & .243 & .022 & .193 \\
\hline Exploration 1 & .190 & .909 & -.065 & .008 \\
\hline Exploration 2 & .135 & .923 & -.011 & -.019 \\
\hline Exploration 3 & .137 & .700 & .041 & .225 \\
\hline Health 1 & .003 & .062 & .860 & -.010 \\
\hline Health 2 & .018 & -.052 & .832 & .060 \\
\hline Health 3 & -.065 & -.036 & .846 & -.068 \\
\hline Convenience 1 & .456 & -.025 & -.053 & .753 \\
\hline Convenience 2 & -.008 & .195 & .054 & .843 \\
\hline Convenience 3 & .498 & .015 & -.061 & .712 \\
\hline $\begin{array}{c}\text { Variance } \\
(75.3 \%): \\
\text { Total \% }\end{array}$ & 21.7 & 19.4 & 18.1 & 16.1 \\
\hline $\begin{array}{l}\text { Cronbach's } \\
\text { alpha }\end{array}$ & 0.850 & 0.795 & 0.817 & 0.769 \\
\hline
\end{tabular}

Table 2: Confirmatory factor analysis result

\begin{tabular}{|c|c|c|c|c|}
\hline Variables & Measure & $\begin{array}{l}\text { Std. factor } \\
\text { loadings }\end{array}$ & CR & AVE \\
\hline \multirow{3}{*}{ Exploration } & Exploration 1 & 0.94 & \multirow{3}{*}{0.83} & \multirow{3}{*}{0.65} \\
\hline & Exploration 2 & 0.895 & & \\
\hline & Exploration 3 & 0.502 & & \\
\hline \multirow{3}{*}{ Health } & Health 1 & 0.826 & \multirow{3}{*}{0.81} & \multirow{3}{*}{0.60} \\
\hline & Health 2 & 0.72 & & \\
\hline & Health 3 & 0.774 & & \\
\hline \multirow{3}{*}{ Convenience } & Convenience 1 & 0.843 & \multirow{3}{*}{0.80} & \multirow{3}{*}{0.58} \\
\hline & Convenience 2 & 0.511 & & \\
\hline & Convenience 3 & 0.869 & & \\
\hline \multirow{3}{*}{ Seasoning } & Seasoning 1 & 0.863 & \multirow{3}{*}{0.85} & \multirow{3}{*}{0.66} \\
\hline & Seasoning 2 & 0.735 & & \\
\hline & Seasoning 3 & 0.827 & & \\
\hline
\end{tabular}

Chi-square $=90.242(p<0.001, \mathrm{df}=48), \mathrm{NFI}=0.943, \mathrm{RFI}=0.908$,

$\mathrm{IFI}=0.973, \mathrm{TLI}=0.955, \mathrm{CFI}=0.972, \mathrm{RMSEA}=0.044$ )

Table 3 shows the discriminant validity through correlation analysis. As a result, as shown in Table 3, the value of square root of AVE is larger than the correlation value outside the diagonal line in the related row and column. Then, the validity of the discrimination has been verified between the different constitutional concepts.

Table 3: Discriminant validity through correlation analysis

\begin{tabular}{|l|l|l|l|l|}
\hline & Seasoning & Exploration & Health & Convenience \\
\hline Seasoning & 0.810 & & & \\
\hline Exploration & 0.365 & 0.803 & & \\
\hline Health & -0.022 & -0.037 & 0.775 & \\
\hline Convenience & 0.650 & 0.092 & -0.061 & 0.759 \\
\hline
\end{tabular}




\subsection{Research Hypothesis Verification}

Using Amos 22.0, the research hypotheses were tested. The fitness index was satisfactory with chi-square $=67.250$ $(\mathrm{df}=48, p<0.001)$, NFI $=0.939$, CFI $=0.981$, and RMSEA $=0.046$ for the study model. Table 4 shows the results of hypotheses for the effects from Hypothesis 1 to Hypothesis 3. In conclusion, the hypothesis test on the main effect, food exploration type, health-oriented type, and convenience-seeking type showed a significant influence on acceptance intention of artificial seasoning. The results are shown in Fig. 2.

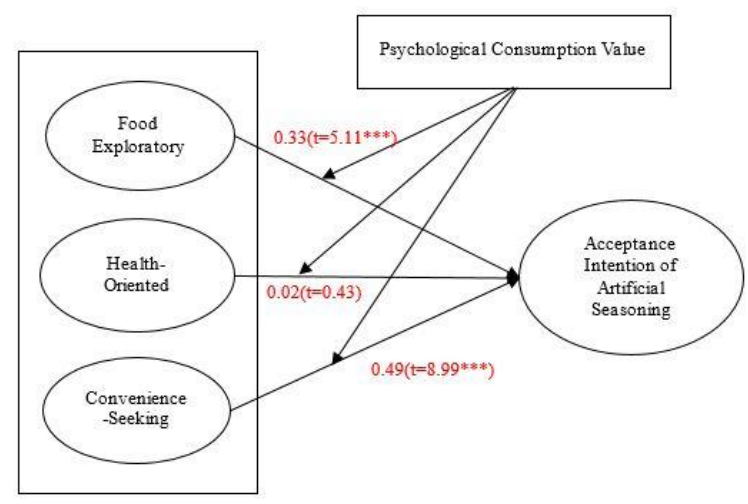

Figure 2: Results of research hypothesis

Table 4: Results of research hypothesis

\begin{tabular}{|c|c|c|c|c|}
\hline Hypothesis & Paths & $\begin{array}{c}\text { Path } \\
\text { Coefficient }\end{array}$ & $\begin{array}{l}\text { T } \\
\text { Value }\end{array}$ & Results \\
\hline $\mathrm{H} 1$ & $\begin{array}{c}\text { Exploration } \rightarrow \\
\text { Seasoning }\end{array}$ & 0.33 & $5.11^{* * *}$ & support \\
\hline $\mathrm{H} 2$ & $\begin{array}{c}\text { Health } \rightarrow \\
\text { Seasoning }\end{array}$ & 0.02 & 0.43 & reject \\
\hline $\mathrm{H} 3$ & $\begin{array}{c}\text { Convenience } \rightarrow \\
\text { Seasoning }\end{array}$ & 0.49 & $8.99^{* * *}$ & support \\
\hline${ }^{*} p<0.05,{ }^{* *} p<0.01,{ }^{* \star *} p<0.001$
\end{tabular}

\subsection{Verifying the Moderating Role of Eating- out Consumption Value}

To examine the effect of consumer eating-out consumption value on the acceptance intention of artificial seasoning, first, the total sample $(\mathrm{n}=300)$ was divided into the hedonic value group and the utilitarian group, and coefficients were compared. Groups were divided into a high hedonic group, low hedonic (utilitarian) group, high utilitarian group, and low utilitarian (hedonic) group based on the average value. Consumers' eating-out consumption value was classified into hedonic value and utilitarian value. Cronbach's alpha of items was 0.81 for hedonic consumption value and 0.60 for utilitarian consumption value.

Table 5 compares the standardized path coefficients of the hedonic motivational group and utilitarian motivational group. The results showed that the hedonic motivational group had more influence on the food exploratory and health-oriented type eating-out style than the utilitarian motivational group. In case of the convenience-seeking type of eating-out style showed that the utilitarian motivational group had more influence than the hedonic motivational group. However, there was significant difference in the effect of the food exploratory type and health-oriented type of the eating-out style on the intention to use artificial seasoning as a result of comparing Chi-square increment value and $p$ value. Therefore, the hypothesis that the effect of eating-out style on the intention of using artificial seasoning would be different according to food consumption value was proved.

Table 5: Comparison of hedonic value group and utilitarian value group

\begin{tabular}{|c|c|c|c|c|c|}
\hline & \multicolumn{2}{|c|}{$\begin{array}{l}\text { Standardized } \\
\text { Regression } \\
\text { Coefficient }\end{array}$} & \multirow{2}{*}{$\begin{array}{c}\text { Comparison } \\
\text { Results }\end{array}$} & \multirow{2}{*}{$\begin{array}{l}\text { Chi- } \\
\text { square } \\
\text { Increm } \\
\text { ent }\end{array}$} & \multirow{2}{*}{$\begin{array}{c}p- \\
\text { value }\end{array}$} \\
\hline & $\begin{array}{l}\text { Hedo- } \\
\text { nic }\end{array}$ & $\begin{array}{l}\text { Utili- } \\
\text { tarian }\end{array}$ & & & \\
\hline $\begin{aligned} & \text { Exploration } \\
\rightarrow & \text { Seasoning }\end{aligned}$ & 0.563 & 0.072 & Hed > Util & $\begin{array}{l}4.482 \\
(d=1)\end{array}$ & $0.034^{*}$ \\
\hline $\begin{array}{l}\text { Health } \rightarrow \\
\text { Seasoning }\end{array}$ & 0.332 & 0.045 & Hed $>$ Util & $\begin{array}{l}5.638 \\
(d=1)\end{array}$ & $0.018^{*}$ \\
\hline $\begin{array}{l}\text { Convenience } \\
\rightarrow \text { Seasoning }\end{array}$ & 0.441 & 0.694 & Hed $<$ Util & $\begin{array}{l}1.262 \\
(d=1)\end{array}$ & 0.261 \\
\hline
\end{tabular}

\section{Conclusion}

The purpose of this study was to determine which eating-out type had more effect on the acceptance intention of artificial seasoning. Based on the literature overview and examination of causality, where lifestyle leads to acceptance intention of artificial seasoning, three eating-out types are considered to be most suitable. The results suggest that food exploratory type and convenience-seeking type have significant effects on acceptance intention of artificial seasoning $(p<0.001)$. However, these relationships differed in consumption value. In terms of the effect of food exploratory type on acceptance intention of artificial seasoning, both the hedonic group and utilitarian group had a positive influence, but the hedonic-oriented consumer group had a statistically greater influence $(p=0.034)$.

\section{Discussion}

The effect of health-oriented type on acceptance intention of artificial seasoning was shown to have a positive effect on both the hedonic consumption value group and the utilitarian consumption value group. However, the hedonic consumer groups had a greater impact than the other group ( $p=0.018)$ statistically. The effect of the convenience-seeking type on acceptance intention of 
artificial seasoning was found to be affected by the utilitarian consumption value group $(0.694)$ more than the hedonic consumption value group (0.441), but this influence did not reach statistical significance. These results suggest that the eating-out type affected by psychological consumption value differs in terms of the usage of artificial seasoning. Therefore, the hedonic value-oriented consumer group is more influenced by the food exploratory type and health-oriented type, while the utilitarian value-oriented consumer group is more influenced by the convenience seeking type. Finally, customers who value hedonic consumption values do not have a reluctance to accept artificial seasonings even if they are health oriented. Therefore, companies should try to expand the entertainment factor of the restaurant and give pleasure to the customers in order to get rid of consumers' repulsion of artificial seasoning.

\section{Implications and Limitations}

These results suggest that consumers who value hedonic consumption value are tolerant of artificial seasonings, even though they are of the health-oriented type. Food exploratory-type consumers also showed higher acceptance intention of artificial seasonings in consumer groups with preference for hedonic consumption value. Foodservice companies should select the proper cooking method, considering consumers' perceptions of artificial seasoning and lead the dining culture according to consumers' preferences and desires.

This study has a few limitations that should be mentioned in future research. In this study, only food exploratory-type, health-oriented type, and convenienceseeking type were judged to be the most important eatingout types in the model construction. Furthermore, more complex and integrated study would be needed to add more varied eating-out types such as the economy-seeking type, among others. Second, in this study, psychological consumption value was classified into the hedonic valueoriented consumer group and the utilitarian value-oriented consumer group. However, in further research, it would be necessary to study other value dimensions based on research of restaurant consumer values.

\section{Reference}

Babin, B. J., Griffin, M., \& Babin, L. (1994). The effect of motivation to process on consumers' satisfaction reactions. ACR North American Advances, 21, 406-411.

Bagozzi, R. P., \& Yi, Y. (1988). On the evaluation of structural equation models. Journal of the Academy of Marketing Science, 16(1), 74-94.

Batra, R., \& Ahtola, O. T. (1991). Measuring the hedonic and utilitarian sources of consumer attitudes. Marketing
Letters, 2(2), 159-170.

Bearden, W. O., Sharma, S., \& Teel, J. E. (1982). Sample size effects on chi square and other statistics used in evaluating causal models. Journal of Marketing Research, 425-430.

Bellenger, D. N., Steinberg, E., \& Stanton, W. W. (1976). Congruence of store image and self image: As it relates to store loyalty. Journal of Retailing, 52(1), 17-32.

Beyreuther, K., Biesalski, H. K., Fernstrom, J. D., Grimm, P., Hammes, W. P., Heinemann, U., \& Walker, R. (2007). Consensus meeting: monosodium glutamate: An update. European Journal of Clinical Nutrition, 61(3), 304.

Buckley, M., Cowan, C., \& McCarthy, M. (2007). The convenience food market in Great Britain: Convenience food lifestyle (CFL) segments. Appetite, 49(3), 600-617.

Cha, S. S., \& Lee, S. H. (2018). The effects of HMR selection attributes on repurchase intention by shopping channels. Journal of Distribution Science, 16(3), 1-10.

Cha, S. S., Oanh, V., \& Yu, W. J. (2018). The effect of eating-out motives on restaurant attributes at shopping mall. Journal of Distribution Science, 16(1), 37-46.

Cha, S. S., \& Park, C. (2017). Consumption value effects on shopping mall attributes: Moderating role of on/off-line channel type. Journal of Distribution Science, 15(6), 512.

Cha, S. S., \& Seo, B. K. (2018). The factors influencing customer satisfaction with and revisiting coffee shops in Korea. Culinary Science \& Hospitality Research, 24(2), $1-7$.

Choe, J. S., Chun, H. K., Hwang, D. Y., \& Nam, H. J. (2005). Consumer perceptions of food-related hazards and correlates of degree of concerns about food. Journal of the Korean Society of Food Science and Nutrition, 34(1), 66-74.

Choe, J. S., \& Kang, H. J. (2005). Eating habits and attitudes of adults in the rural area by socioeconomic factors. The Korean Journal of Community Living Science, 16(1), 49-58.

Choi, S. Y. (2005). Consumer attitudes and choices made in hotel restaurants over a five-day workweek: Focused on domestic consumers at a hotel buffet restaurant in Seoul. Korean J Foodservice Management, 8, 27-45.

Chung, H. K., Yang, H. J., Shin, D., \& Chung, K. R. (2016). Aesthetics of Korean foods: The symbol of Korean culture. Journal of Ethnic Foods, 3(3), 178-188.

Churchill Jr., G. A. (1979). A paradigm for developing better measures of marketing constructs. Journal of Marketing Research, 64-73.

Fischer, E., \& Arnold, S. J. (1990). More than a labor of love: Gender roles and Christmas gift shopping. Journal of Consumer Research, 17(3), 333-345.

Freeman, M. (2006). Reconsidering the effects of monosodium glutamate: A literature review. Journal of the American Association of Nurse Practitioners, 18(10), 482-486.

Grunert, K. G., Brunso, K., \& Bisp, S. (1993). Food-related 
life style: Development of a cross-culturally valid instrument for market surveillance. Århus, Denmark: MAPP.

Hirschman, E. C., \& Holbrook, M. B. (1982). Hedonic consumption: Emerging concepts, methods and propositions. The Journal of Marketing, 92-101.

Jeong, H. Y., \& Jeong, N. H. (2009). Recognition of food additives of high school students in Gwangju. Journal of Korean Home Economics Education Association, 21, 117.

Kil, G. Y., \& Jin, S. Y. (2015). A survey of awareness and preference for MSG according to the pursuit of wellbeing in diet. Journal of the Korean Society of Food Culture, 30(5), 481-490.

Kim, H. C., \& Kim, M. R. (2010) Analysis on the effect of dietary lifestyle on consumption pattern of soybean paste among housewives, The Korean Journal of Culinary Research, 16(3), 76-93.

Kim, K. H. (2010). Effect of a food-related lifestyle on the consumption of and satisfaction with Korean foods, and intention to revisit. Journal of Korean Contents Study, 10(8), 370-380.

Kim, Y. G., Kim, Y. J., \& Cho, H. S. (2013). The effects of allowable range of the MSG and awareness of the usage on the consumer's purchase intention. Foodservice Management Study, 16, 241-259.

Ko, J. Y., Song, H. J., \& Woo, J. R. (2007). Segmenting female customers market visiting family restaurant through eating out motivation, Journal of Foodservice Management, 10(1), 71-89.

Lee, A. J. (2007). A study on consumer's choice attributes of Korean style restaurants based on consumer's diningout motives, Journal of Hotel Resort, 6(2), 209-220.

McGrath, M. A., Sherry, J. F., \& Levy, S. J. (1993). Giving voice to the gift: The use of projective techniques to recover lost meanings. Journal of Consumer Psychology,
2(2), 171-191.

Myung, C. O., Nam, H. W., \& Park, Y. S. (2016) Purchasing behaviors and needs for HMR according to the food-related lifestyles of baby boomer women. The Korean Journal of Food and Nutrition, 29(1), 87-103.

Nunnally, J. C., \& Bernstein, I. H. (1978). Psychometric theory. New York: McGraw-Hill.

Park, S. H., Park, J. H., \& Oh, L. K. (2011). The effects of a silver generation's lifestyle on restaurant selection attributes. Journal of Tourism Management, 26(3), 149170.

Rohm, A. J., \& Swaminathan, V. (2004). A typology of online shoppers based on shopping motivations. Journal of Business Research, 57(7), 748-757.

Schultz, D. E. (1993). Integrated marketing communications: Maybe definition is in the point of view. Marketing News, 27(2), 17.

Strahilevitz, M., \& Myers, J. G. (1998). Donations to charity as purchase incentives: How well they work may depend on what you are trying to sell. Journal of Consumer Research, 24(4), 434-446.

Swoboda, B., \& Morschett, D. (2001). Convenienceoriented shopping: a model from the perspective of consumer research. In Food, People and Society (pp. 177-196). Berlin, Germany: Springer.

Van, J. W. (2008). A study on eating-out behavior by cluster analysis according to the lifestyle of female consumers in Seoul. Journal of the Korean Society of Food Culture, 23(3), 377-387.

Yang, W. J., \& Park, H. J. (2002). A study on the relationship of the fast food selection attributes and the use behaviors. Korean Journal of Tourism and leisure, 12(2), 107-124.

Yim, Y. M., \& Yoon, H. H. (2006). A study on the foodrelated life style to wine selection attribution. Korea Tour Res Assoc, 20(3), 289-300. 